\title{
Structure and Basicity of Microporous Titanosilicate ETS-10 and Vanadium-Containing ETS-10
}

\author{
Meiling Guo, ${ }^{\dagger \ddagger}$ Evgeny A. Pidko, ${ }^{\S}$ Fengtao Fan, ${ }^{\dagger}$ Zhaochi Feng, $^{\dagger}$ Jan P. Hofmann, ${ }^{\perp}$ \\ Bert M. Weckhuysen, ${ }^{\perp}$ Emiel J. M. Hensen, ${ }^{*} \S$ and Can $\mathrm{Li}^{*}, \dagger$ \\ ${ }^{\dagger}$ State Key Laboratory of Catalysis, Dalian Institute of Chemical Physics, Chinese Academy of Sciences, 457 Zhongshan Road, Dalian,
116023 , China
${ }^{\ddagger}$ Graduate University of Chinese Academy of Sciences, 457 Zhongshan Road, Dalian, 116023, China
${ }^{\S}$ Inorganic Materials Chemistry, Schuit Institute of Catalysis, Eindhoven University of Technology, P.O. Box 513, 5600 MB
Eindhoven, The Netherlands
${ }^{\perp}$ Inorganic Chemistry and Catalysis, Debye Institute for NanoMaterials Science, Utrecht University, Universiteitsweg 99,3584 CG
Utrecht, The Netherlands
}

Supporting Information

ABSTRACT: ETS-10 has attracted considerable attention as a base catalyst. It is desirable to confirm the location of basic sites. Vanadium-substituted ETS-10 also attracts much attention for the interesting feature that the Ti can be fully replaced by $\mathrm{V}$ without changing its topology. It is important to characterize the local environment upon $\mathrm{V}$ substitution for understanding the property and reactivity of ETVS-10. The structural and acid-base properties of pure titanosilicate ETS-10 and a series of vanadium-substituted ETVS-10 with different framework V content were studied by a combination of Raman spectroscopy and FTIR of absorbed acetylene and carbon monoxide as molecular probes. The substitution of up to $70 \%$ of $\mathrm{Ti}$ atoms with $\mathrm{V}$ in the structure of ETS-10 results in ETVS-10 materials with a homogeneous distribution of $\mathrm{Ti}$ and $\mathrm{V}$ species. At higher $\mathrm{V}$ concentrations, a distinct phase separation between the vanadium-rich domains is observed. The intrinsic
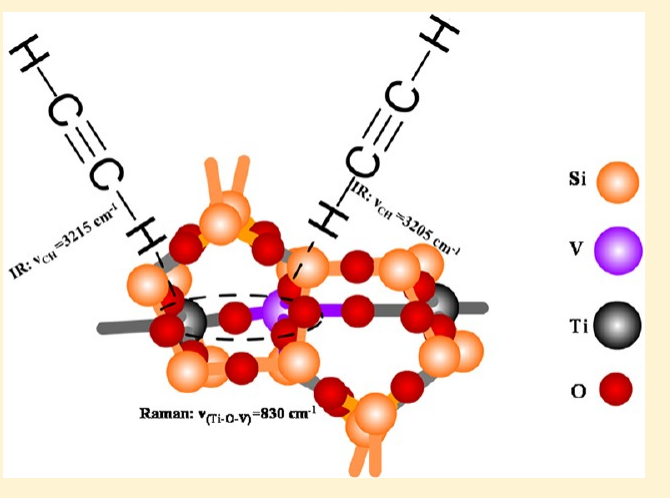
basicity of ETVS-10 as revealed by FTIR spectroscopy of adsorbed $\mathrm{C}_{2} \mathrm{H}_{2}$ gradually increases with the increasing V content. It is shown that the specific basicity of the ETS-10 lattice is mainly associated with the presence of highly basic oxygen centers adjacent to the lattice defects. Liquid phase Knoevenagel condensation of benzaldehyde with ethyl cyanoacetate was used as a test reaction to investigate the catalytic reactivity of different basic sites in the synthesized materials. The reactivity of the materials considered in the base-catalyzed Knoevenagel condensation is determined not only by the strength of the basic sites but also by their density. The optimum combination of both factors is achieved for the ETVS-10 material with $\mathrm{V} /(\mathrm{Ti}+\mathrm{V})$ ratio of $70 \%$.

\section{INTRODUCTION}

The microporous titanosilicate ETS-10 is a base catalyst that has been used in the dehydration of tert-butyl alcohol, ${ }^{1-3}$ the dehydrogenation of alcohols such as ethanol, 2-propanol, and cyclohexanol, ${ }^{3,4}$ the aldol condensation of acetone, ${ }^{5,6}$ and the isomerization of glucose. ${ }^{7}$ Compared to the well-understood Brønsted acidity in zeolites, ${ }^{8}$ the nature and reactivity of basic sites in these materials remain a subject of debate. In ETS-10, one identifies octahedral $\mathrm{Ti}^{4+}$ ions besides tetrahedral framework $\mathrm{Si}^{4+}$ ions. ${ }^{9}$ Each $\left[\mathrm{TiO}_{6}\right]$ lattice unit bears two negative charges, which are usually balanced by exchangeable $\mathrm{Na}^{+}$and $\mathrm{K}^{+}$ions.

Adsorption of small probe molecules in combination with vibrational spectroscopy is a widely used technique to study the acid-base properties of active sites in heterogeneous catalysts. ${ }^{10-12}$ Acetylene has been used for estimating the strength of basic sites by FTIR spectroscopy. Upon adsorption, the rather acidic $\mathrm{CH}$ moiety of $\mathrm{C}_{2} \mathrm{H}_{2}$ forms weak hydrogen bonds with basic lattice oxygen sites. In addition, the electronrich $\pi$-system of acetylene can interact with Lewis acidic cations. As a result the properties of the molecular probe interacting with the basic sites can be substantially influenced by the interaction with the neighboring Lewis acid. Coadsorption of two different probe molecules, one of which is able to selectively bind with the latter sites, represents a potential route for analysis of the intrinsic basicity of heterogeneous catalysts. ${ }^{12} \mathrm{CO}$ is such a probe molecule that can be used to selectively characterize the Lewis acidic alkali cations in zeolites. ${ }^{13,14}$ Thus, by coadsorbing CO and acetylene,

Received: June 6, 2012

Revised: July 24, 2012

Published: July 24, 2012 
it seems plausible to separately probe Lewis acidic and basic sites.

The chemical properties of ETS-10 can be adjusted not only by varying the extraframework cationic species, but also by substituting some of the lattice $\mathrm{Ti}$ and $\mathrm{Si}$ atoms by other transition metals. ${ }^{3,15-23}$ For example, vanadium-substituted ETS-10 (ETVS-10) have attracted much attention because of their interesting chemical properties and potential application as photocatalysts. ${ }^{16,19-23}$ An attractive feature of V-substituted ETS-10 is the possibility to widely vary the ratio between $\mathrm{Ti}$ and $\mathrm{V}$ atoms in the framework without changing its topology. In the absence of $\mathrm{Ti}$, the vanadosilicate AM-6 is obtained, which is isostructural to ETS-10. ${ }^{24}$

It is desirable to identify the location of the basic sites and the interaction of Lewis acidic and basic sites of ETS-10. It is also very important to characterize the changes in the local environment and basicity upon the $\mathrm{V}$ substitution. In this contribution, the basic properties of ETS-10 were studied by FTIR spectroscopy of absorbed acetylene and carbon monoxide, complemented by DFT calculation. The distribution of Ti and V atoms in ETVS-10 materials is analyzed by Raman microspectroscopy. The base-catalyzed liquid phase Knoevenagel condensation of benzaldehyde with ethyl cyanoacetate was used as a test reaction to evaluate the catalytic reactivity of basic sites in different ETVS-10.

\section{EXPERIMENTAL SECTION}

Synthesis. A typical synthesis of ETVS-10 was performed as follows. Mixture A was prepared by mixing $5.8 \mathrm{~mL}$ of sodium silicate solution (20 wt \% $\mathrm{SiO}_{2}, 6.9$ wt $\% \mathrm{Na}_{2} \mathrm{O}$ ), $\mathrm{NaOH}(1.69$ $\mathrm{g}$ ), and $\mathrm{K}_{2} \mathrm{SO}_{4}(1.6 \mathrm{~g})$ in $10 \mathrm{~mL}$ of deionized water with stirring for $30 \mathrm{~min}$. Concentrated $\mathrm{H}_{2} \mathrm{SO}_{4}(0.66 \mathrm{~mL})$ was added to $\left[\mathrm{Ti}(\mathrm{iPrO})_{4}\right]$ with stirring for $5 \mathrm{~min}$, followed by addition of 15 $\mathrm{mL}$ of deionized water. This mixture was boiled for $10 \mathrm{~min}$ to obtain anatase nanoparticles used as the titanium source. Subsequently, a vanadate solution $\left(\mathrm{VOSO}_{4}\right)$ was slowly added to the solution containing the anatase nanoparticles in a dropwise manner to obtain mixture B. The molar ratio of (V $+\mathrm{Ti}) / \mathrm{Si}$ is 5.02 for a series of ETVS-10 with different $\mathrm{V}$ content. The two mixtures A and B were then mixed under stirring for $30 \mathrm{~min}$ to obtain the final gel. For the synthesis of ETVS-10 with V contents of 0.9 and 1.0, a small amount of ETS-10 (10 mg) was added to the gel as seeds for crystallization. Finally, the gel was transferred into a Teflonlined stainless steel autoclave and placed in an oven for $12 \mathrm{~h}$ at $230{ }^{\circ} \mathrm{C}$. The sample was filtered and washed with deionized water and dried overnight at $80{ }^{\circ} \mathrm{C}$. The following notation is used to differentiate the ETVS-10 materials investigated in this work: ETVS-10 $(x)$, where $x$ corresponds to the $\mathrm{V} /(\mathrm{V}+\mathrm{Ti})$ molar ratio in the initial gel.

Characterization. XRD patterns were recorded on a Rigaku D/Max-2500/PC powder diffractometer. Each sample powder was scanned by using $\mathrm{Cu} \mathrm{K} \alpha$ radiation with an operating voltage of $40 \mathrm{kV}$ and an operating current of $200 \mathrm{~mA}$. $2 \theta$ angles from $5^{\circ}$ to $40^{\circ}$ were measured with the speed of 5 $\mathrm{deg} / \mathrm{min}$. The catalysts were ground and pressed in sample holders for measurements. The morphology of the synthesized samples was examined with use of Scanning Electron Microscopy (SEM). SEM images were collected with a QUANTA 200F electron microscope. Visible Raman spectra were collected on a homemade Raman spectrograph system. The scattered light was collected by the ellipse collecting mirror in a backscattering geometry and focused into the entrance of the Raman spectrograph. The Raman spectra were collected with a spectral resolution of $2 \mathrm{~cm}^{-1}$ with the laser excitation at $532 \mathrm{~nm}$ from semiconductor lasers. Raman microspectroscopy imaging was carried out on a Renishaw inVia Raman microscope at $100 \times$ magnification, using StreamLine mode at $514 \mathrm{~nm}$ Ar ion laser excitation. For imaging, characteristic Raman bands have been selected and their intensity was mapped according to the band height. FTIR spectra were recorded with a Bruker Vertex V70 FTIR spectrometer in transmission mode. Typically, an about 10-mg sample was pressed into a self-supporting wafer and placed in a controlledenvironment transmission cell. Prior to recording the spectra, the samples were dehydrated in vacuum at $300{ }^{\circ} \mathrm{C}$ (ramp 5 $\mathrm{deg} / \mathrm{min}$ ). After an isothermal period of $2 \mathrm{~h}$ at $300{ }^{\circ} \mathrm{C}$ the sample was cooled to room temperature in a vacuum. The spectra of adsorbed acetylene were recorded at room temperature and at different equilibrium pressures. The spectra of adsorbed CO were collected at $-150{ }^{\circ} \mathrm{C}$. After that, acetylene was introduced to the cell, and the spectra of adsorbed $\mathrm{CO}$ and acetylene were collected at $-150{ }^{\circ} \mathrm{C}$.

DFT Calculations. A $21 \mathrm{~T}$ cluster (102 atoms) was used to model the sample-acetylene complexes (Figure S1, Supporting Information). Different possible adsorption sites of ETS-10 were compared. Dangling $\mathrm{Si}-\mathrm{O}$ bonds of the model were saturated by $\mathrm{H}$ atoms located $1.4 \AA$ from each terminal $\mathrm{Si}$ atom. $\mathrm{Ti}$ defect sites were modeled as $\mathrm{Ti}-\mathrm{OH}$ at the periphery of the cluster. Full geometry optimization was performed for the cluster model and acetylene with the exception that the positions of boundary $\mathrm{H}$ were fixed according to their initial coordinates. Calculations were performed at the M06L/6$31 \mathrm{G}(\mathrm{d}, \mathrm{p})$ level of theory, using Gaussian 09 program. Vibrational frequencies were computed analytically from the normal-mode analysis involving all atoms of the model in the harmonic approximation.

Basicity Tests. Liquid phase Knoevenagel condensation was used to test the basicity of the ETVS-10. The reactions were carried out in a $25 \mathrm{~mL}$ round-bottomed flask equipped with a Dimroth condenser. The reaction mixture was continuously stirred with a magnetic stirrer. Quantitative analyses of the products were performed on a gas chromatograph. For the reaction, $5 \mathrm{mmol}$ of benzaldehyde (BA) and $5 \mathrm{mmol}$ of ethyl cyanoacetate (ECA) were mixed with $7.5 \mathrm{~mL}$ of ethanol and 2.5 mmol of $n$-decane as the internal standard. After mixing $30 \mathrm{mg}$ of catalyst to this solution, the suspension was heated to $60{ }^{\circ} \mathrm{C}$ for $1 \mathrm{~h}$. The product was ethyl $\alpha$-cyanocinnamate (ECC) as determined by GC-FID.

\section{RESULTS AND DISCUSSION}

Acid-Base Property of ETS-10. FTIR spectroscopy was used to investigate the basic properties of ETS-10 with acetylene as molecular probe (Figure 1). Adsorption of $\mathrm{C}_{2} \mathrm{H}_{2}$ on ETS-10 leads to the formation of two bands at 3212 and $3229 \mathrm{~cm}^{-1}$, denoted as LF (low frequency) and HF (high frequency), respectively. These bands correspond to the $\nu_{3}$ stretching vibrations of adsorbed acetylene. Because the relative intensities of these bands change independently with increasing $\mathrm{C}_{2} \mathrm{H}_{2}$ pressure, we assign them to acetylene molecules adsorbed on different sites of ETS-10. The strong perturbation of adsorbed $\mathrm{C}_{2} \mathrm{H}_{2}$ is apparent from the strong red shifts of the $\nu_{3}$ stretching frequency compared to the gas phase $(-58$ and -75 $\mathrm{cm}^{-1}$, respectively, for the HF and LF bands). Since the LF feature dominates at lower pressures, it can be assigned to the sites of stronger acetylene adsorption. With increasing 


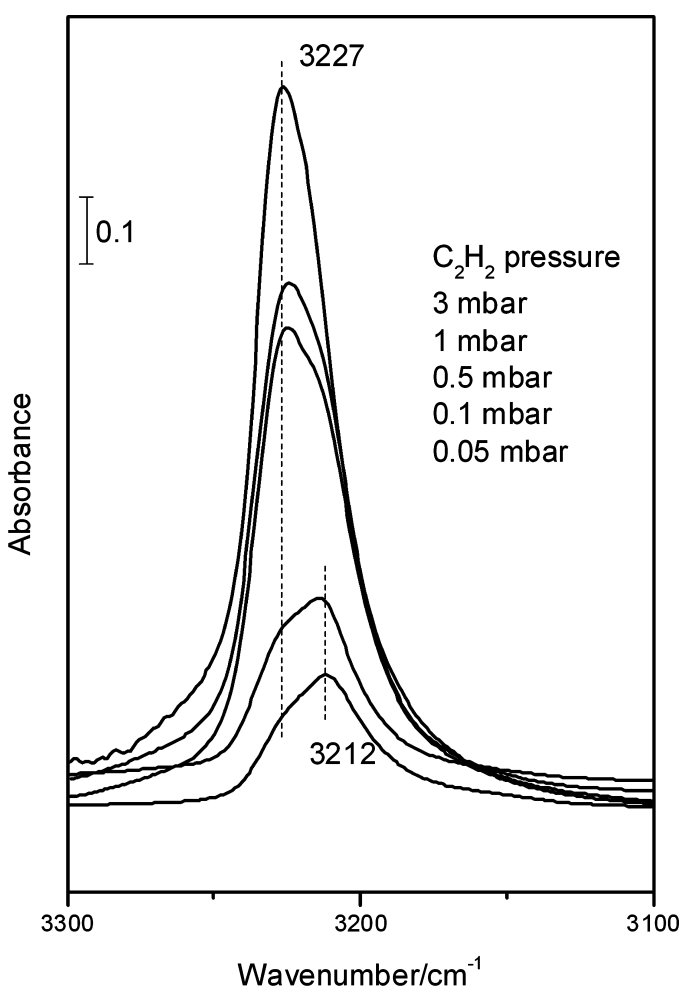

Figure 1. FTIR spectra of acetylene on ETS-10.

acetylene pressure, the sites associated with the LF band become saturated, whereas those characterized by the HF feature are still being populated.

For comparison, adsorption of acetylene to zeolite $\mathrm{NaY}$ was also investigated (Figure S2 Supporting Information). The smaller red shift for the HF and shoulder LF features observed evidence the weaker basicity of $\mathrm{NaY}$ zeolite compared to ETS10. A similar conclusion was drawn by Tatsumi et al. with use of pyrrole as a probe. ${ }^{25}$ For NaY, the HF band at $3245 \mathrm{~cm}^{-1}$ has been ascribed to the $\mathrm{CH}$ vibration of an acetylene $\pi$-complex (the interaction between $\mathrm{C} \equiv \mathrm{C}$ of acetylene and $\mathrm{Na}^{+}$ions), and the LF band at $3215 \mathrm{~cm}^{-1}$ to the H-bonded species. ${ }^{10}$

In view of the similarity of the spectra for $\mathrm{Na}-\mathrm{Y}$ and ETVS10, the HF and LF bands of ETVS-10 can be assigned to the same adsorption modes. To further validate this interpretation, the interaction between ETS-10 and acetylene was studied by model DFT calculations. Ten different starting structures for $\mathrm{C}_{2} \mathrm{H}_{2}$ adsorption complexes at different sites of a cluster model of ETS-10 were constructed. Their geometry optimization

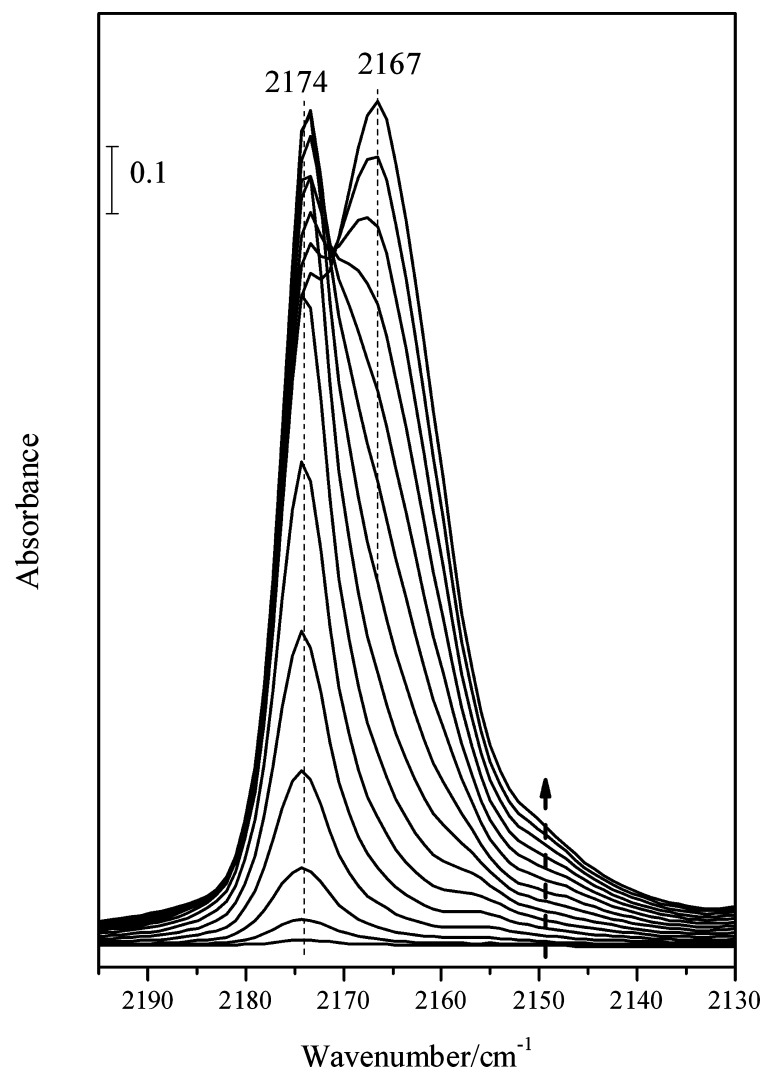

Figure 2. FTIR spectra of CO adsorbed on ETS-10. The dotted arrow indicates an increase in gas-phase equilibrium pressure of $\mathrm{CO}$.

resulted in three distinct configurations, namely, adsorption of acetylene on the $\mathrm{Si}-\mathrm{O}-\mathrm{Si}$ moieties (H-bonded species), on $\mathrm{Na}^{+}$extraframework cations ( $\pi$-complex), and the framework oxygen atom (H-bonded species) adjacent to the $\mathrm{Ti}-\mathrm{OH}$ defects as shown in Scheme 1. Adsorption to the $\mathrm{Si}-\mathrm{O}-\mathrm{Si}$ fragment gives the weakest complex $(24 \mathrm{~kJ} / \mathrm{mol})$, which is characterized by a very small red shift of the asymmetric $\mathrm{CH}$ stretching $\left(-10 \mathrm{~cm}^{-1}\right)$. Most of the initial adsorption configurations lead upon geometry optimization to $\pi$ complexes with extraframework $\mathrm{Na}^{+}$ions. These sites should thus be the dominant adsorption sites for $\mathrm{C}_{2} \mathrm{H}_{2}$. The adsorption energy is $46 \mathrm{~kJ} / \mathrm{mol}$ and the red shift of $\nu_{\mathrm{CH}}$ is $-35 \mathrm{~cm}^{-1}$. The red shift is independent of the local surrounding of the extraframework $\mathrm{Na}^{+}$ions. Adsorption to the basic oxygen sites adjacent to the defect $\mathrm{Ti}-\mathrm{OH}$ fragments leads to the most pronounced perturbation of $\mathrm{C}_{2} \mathrm{H}_{2}$. The adsorption energy (33

Scheme 1. Acetylene Adsorption on (a) $\mathrm{Si}-\mathrm{O}-\mathrm{Si}$ Moieties, (b) $\mathrm{Na}^{+}$Extraframework Cations, and (c) Oxygen Adjacent to the $\mathrm{Ti}-\mathrm{OH}$ Defect Site

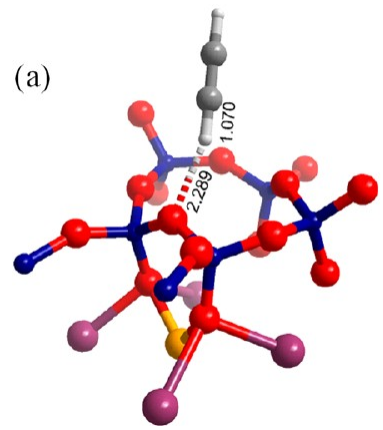

(b)

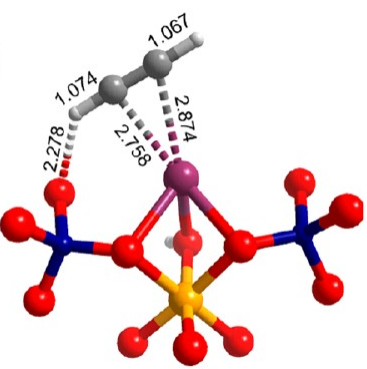

17126

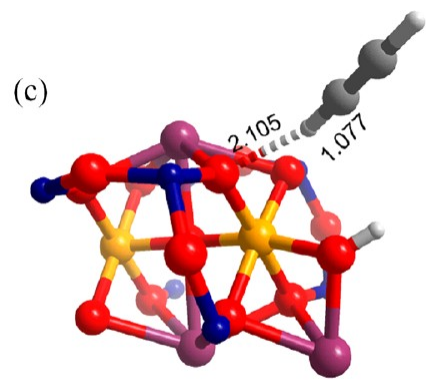

dx.doi.org/10.1021/jp305543m I J. Phys. Chem. C 2012, 116, 17124-17133 

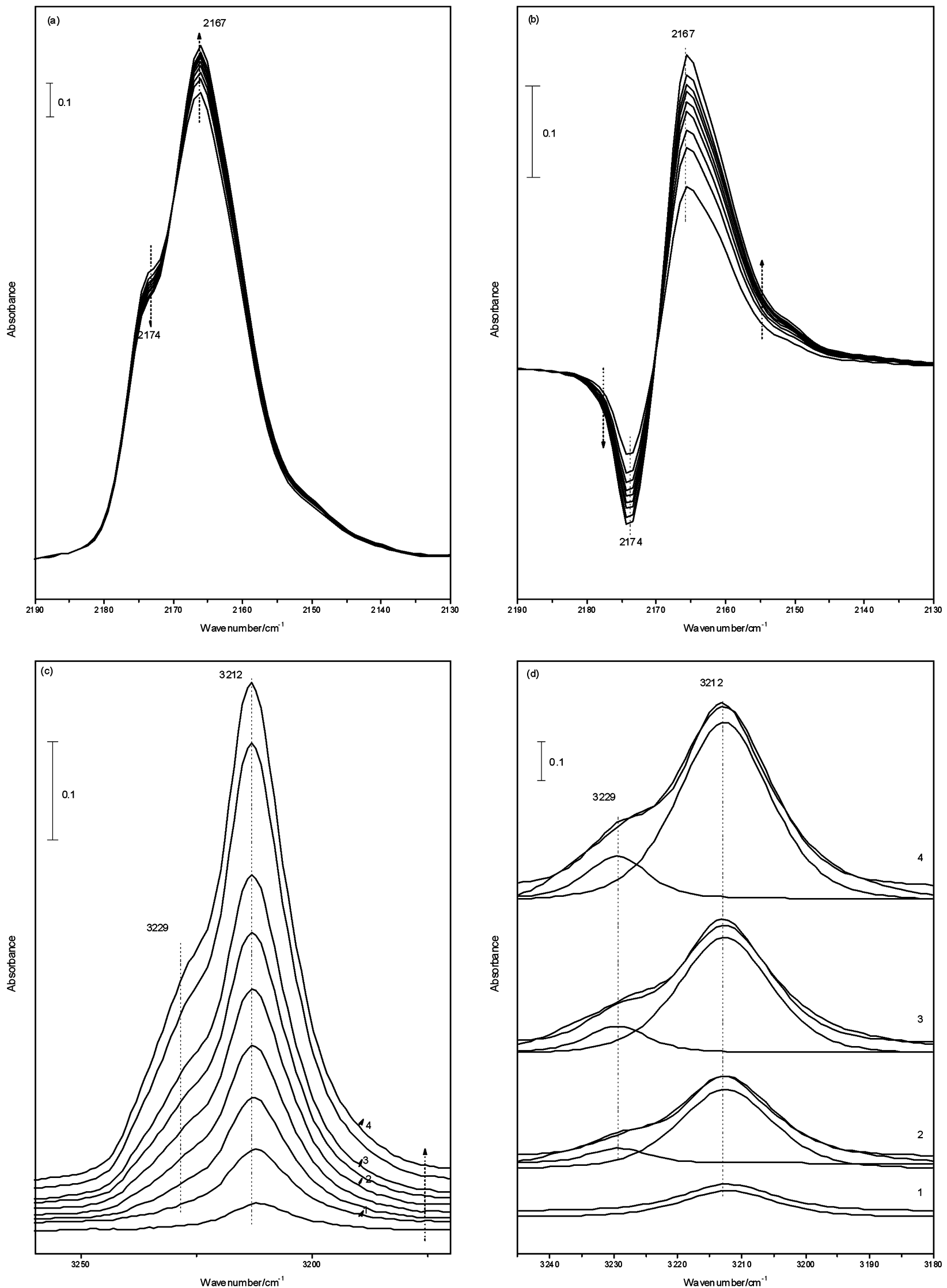

Figure 3. (a) FTIR spectra of CO along with the subsequent adsorption of acetylene to CO on ETS-10, (b) spectral changes in the CO region of part a, (c) FTIR spectra of acetylene along with the subsequent adsorption of acetylene to CO on the ETS-10, and (d) the deconvolution of 1, 2, 3, and 4 in part $c$. 

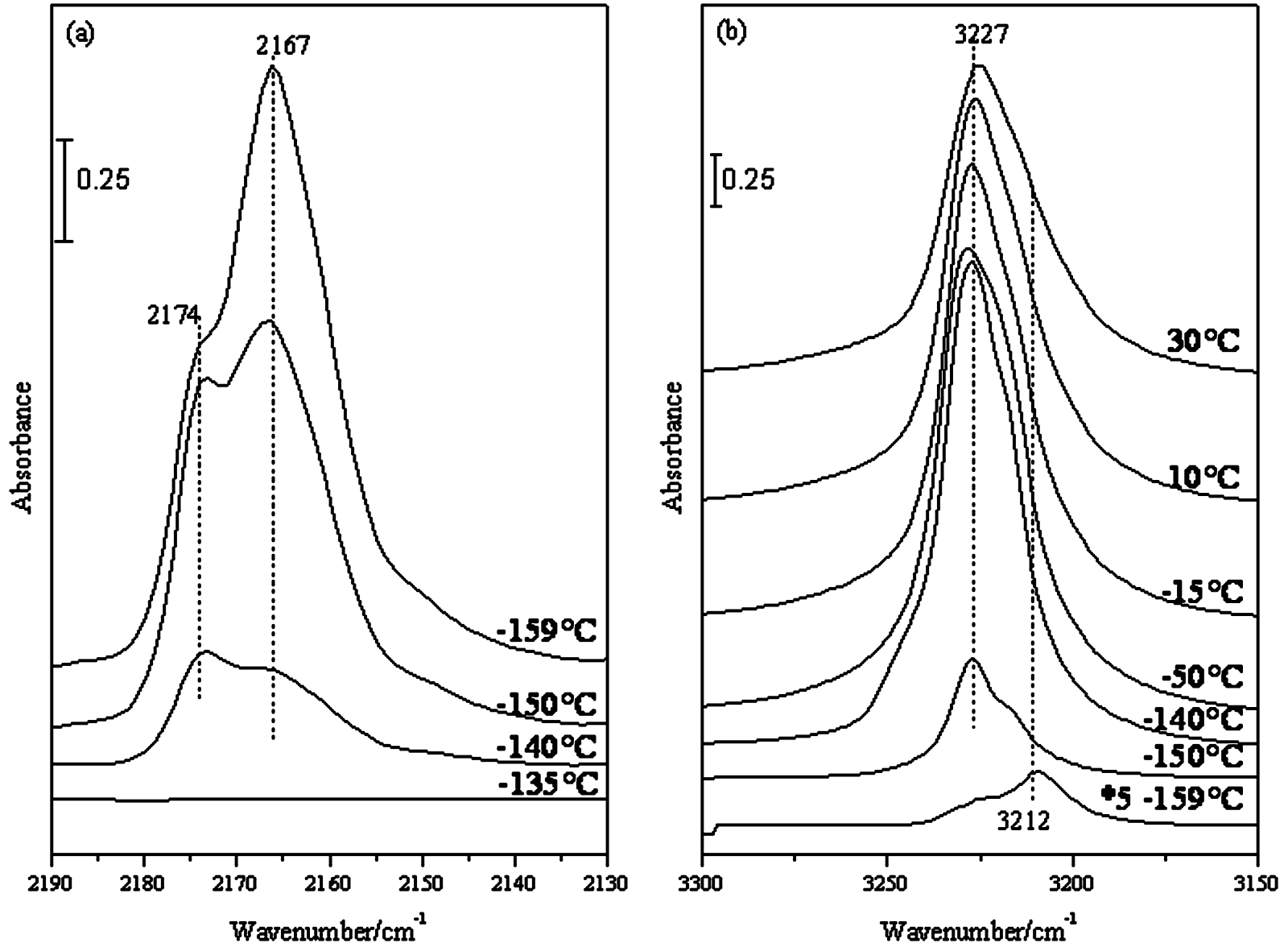

Figure 4. FTIR spectra of (a) CO and (b) acetylene adsorbed to ETS-10 as a function of temperature.

Table 1. Composition of ETVS-10 Samples

\begin{tabular}{|c|c|c|c|c|c|c|c|}
\hline sample & $\begin{array}{c}\text { ETS- } \\
10\end{array}$ & $\begin{array}{l}\text { ETVS- } \\
10(0.1)\end{array}$ & $\begin{array}{l}\text { ETVS- } \\
10(0.3)\end{array}$ & $\begin{array}{l}\text { ETVS- } \\
10(0.5)\end{array}$ & $\begin{array}{l}\text { ETVS- } \\
10(0.7)\end{array}$ & $\begin{array}{l}\text { ETVS- } \\
10(0.9)\end{array}$ & AM-6 \\
\hline $\begin{array}{l}\mathrm{V} /(\mathrm{V} \\
+\mathrm{Ti})\end{array}$ & 0 & 0.08 & 0.21 & 0.39 & 0.57 & 0.78 & 0.97 \\
\hline $\begin{array}{c}\mathrm{K} /(\mathrm{K} \\
+\mathrm{Na})\end{array}$ & 0.22 & 0.34 & 0.13 & 0.20 & 0.11 & 0.16 & 0.16 \\
\hline
\end{tabular}

$\mathrm{kJ} / \mathrm{mol}$ ) is close to that estimated for the case of adsorption to $\mathrm{Na}^{+}$ions. The red shift in this case is $-73 \mathrm{~cm}^{-1}$. The computational results confirm the assignments for HF and LF to the $\pi$-complex and the H-bonded species, respectively. The $\mathrm{Na}^{+}$ions act as Lewis acid centers and the framework oxygen atoms adjacent to the defect $\mathrm{Ti}-\mathrm{OH}$ as basic centers.

To further detail the basic properties of these materials, the strengths of Lewis acidic extraframework cations and basic lattice sites were probed independently by monitoring the coadsorption of $\mathrm{CO}$ and $\mathrm{C}_{2} \mathrm{H}_{2}$, using infrared spectroscopy. These experiments were carried out at $-150{ }^{\circ} \mathrm{C}$. Figure 2 shows the IR spectra of CO adsorbed on ETS-10 with increasing $\mathrm{CO}$ coverage. At low pressures a single band is observed at $2174 \mathrm{~cm}^{-1}$ (denoted as CO-1), which corresponds
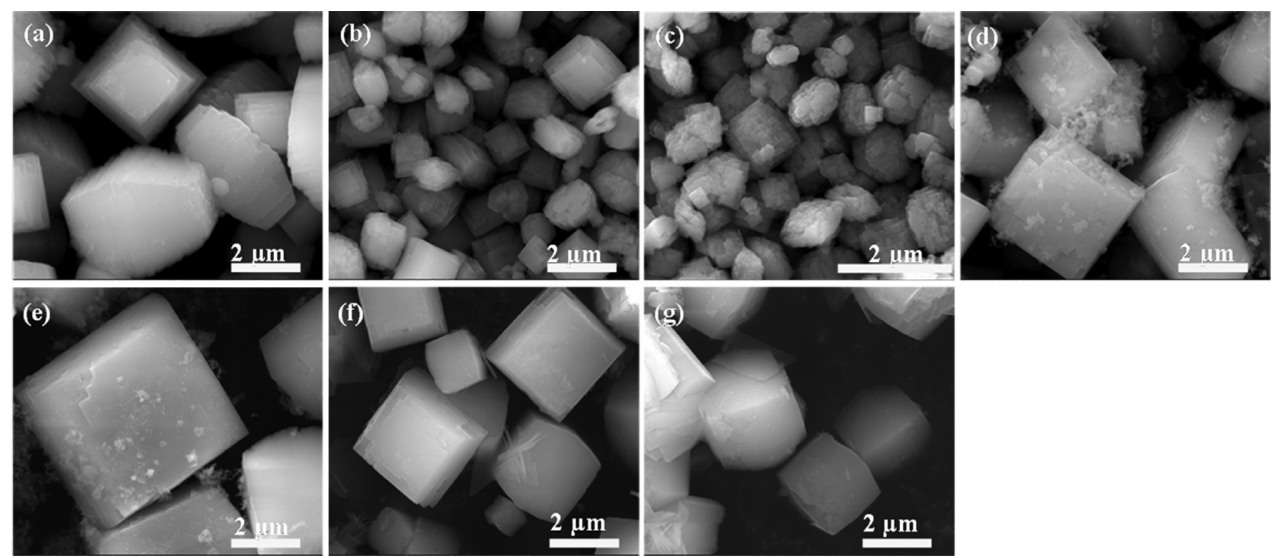

Figure 5. SEM images of (a) ETS-10, (b) ETVS-10(0.1), (c) ETVS-10(0.3), (d) ETVS-10(0.5), (e) ETVS-10(0.7), (f) ETVS-10(0.9), and (g) AM6 samples. 


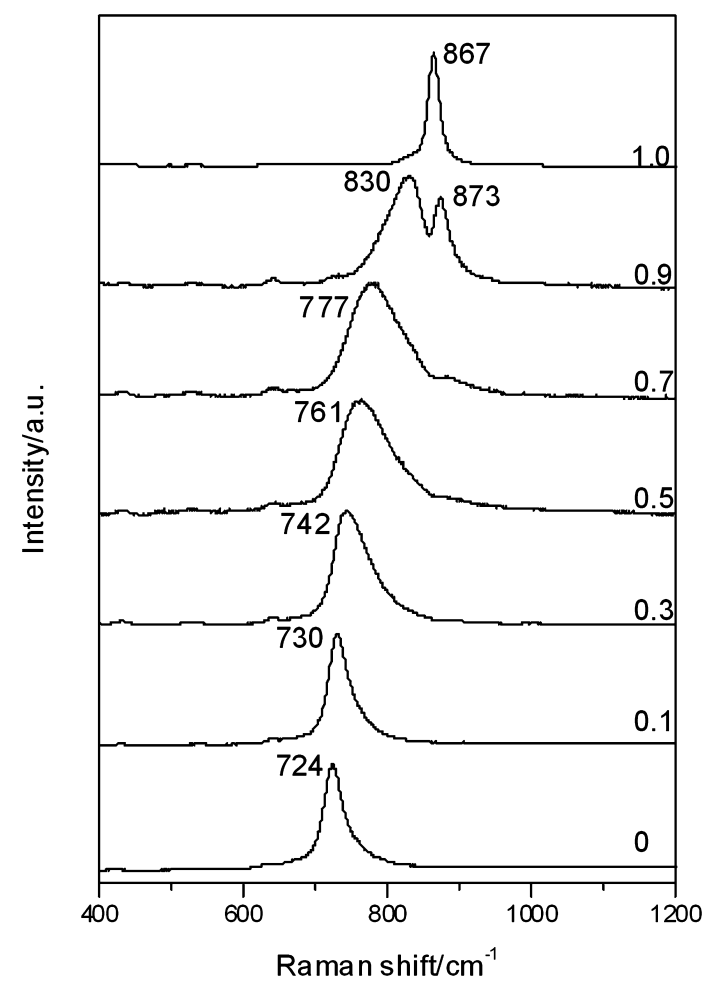

Figure 6. Raman spectra of ETVS-10 with different V content.

Scheme 2. The Relation of the Length of Ti-Rich and the Number of $\mathrm{Ti}-\mathrm{O}-\mathrm{V}$ Junctions along the Wire As a Function of $\mathrm{V}$ Content

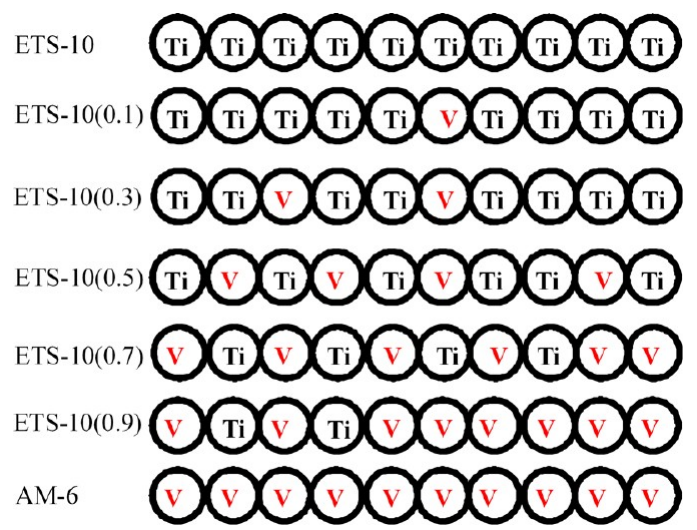

to $\mathrm{CO}$ adsorbed to $\mathrm{Na}^{+}$and $\mathrm{K}^{+}$ions. ${ }^{26}$ In agreement with the literature, ${ }^{26}$ it is seen that the increase of the $\mathrm{CO}$ coverage leads to a decrease of the band intensity at $2174 \mathrm{~cm}^{-1}$ and a concomitant increase of the band intensity at $2167 \mathrm{~cm}^{-1}$ (denoted as CO-2). The occurrence of an isosbestic point implies that these two bands are related to the common adsorption site. The band at lower wavenumber is due to multiple $\mathrm{CO}$ adsorptions to the exchangeable alkali cations. ${ }^{26}$

Subsequent introduction of acetylene to ETS-10 with adsorbed $\mathrm{CO}$ leads to minor changes of the $\mathrm{CO}$ stretching modes (Figure 3a,b). The intensity of CO-2 increases slightly, while the CO-1 intensity decreases with increasing $\mathrm{C}_{2} \mathrm{H}_{2}$ coverage. The corresponding changes in the $\mathrm{CH}$ stretching region are shown in panels $\mathrm{c}$ and $\mathrm{d}$ of Figure 3. At very low $\mathrm{C}_{2} \mathrm{H}_{2}$ pressure, only the LF band is observed (Figure $3 \mathrm{~d}, 1$ ). With increasing acetylene pressure, a distinct shoulder at higher frequencies (HF) appears (Figure $3 \mathrm{c}, \mathrm{d}$ ). These observations are in good agreement with our hypothesis that $\mathrm{CO}$ preferentially adsorbs to the $\mathrm{Na}^{+}$ions sites and $\mathrm{C}_{2} \mathrm{H}_{2}$ to the basic framework oxygen atoms. The slight variations observed in the spectrum of adsorbed $\mathrm{CO}$ are probably associated with the repulsive interaction between adsorbed $\mathrm{C}_{2} \mathrm{H}_{2}$ and $\mathrm{CO}$ at the adjacent sites, which leads to the displacement of $\mathrm{CO}$ from its initial adsorption site.

The results in Figure 4 indicate that upon the temperature increase, CO desorbs from the ETS-10 and the Lewis acid sites are occupied mainly by acetylene. The weaker multiple-CO adsorption complexes are decomposed much faster than the monomeric complexes. Complete $\mathrm{CO}$ desorption is achieved already at $-135{ }^{\circ} \mathrm{C}$ (Figure 4a). Upon the introduction of $\mathrm{C}_{2} \mathrm{H}_{2}$ at $-150{ }^{\circ} \mathrm{C}$, a substantial part of acetylene does not reach the sample and is being frozen on the cold part of the sample holder. A slight increase in temperature readily leads to the pronounced increase of the intensity of the HF band (Figure $4 \mathrm{~b}$ ) associated with the adsorption of $\mathrm{C}_{2} \mathrm{H}_{2}$ to extraframework cations that became available after desorption of $\mathrm{CO}$. At room temperature, the spectra resemble closely those recorded for pure $\mathrm{C}_{2} \mathrm{H}_{2}$ adsorption as indicated in Figure 1 .

Composition of ETVS-10. A series of V substituted ETS10 samples were prepared to adjust the property of ETS-10 (XRD patterns shown in Figure S3, Supporting Information). The elemental composition of the ETVS-10 samples determined by means of ICP analysis is summarized in Table 1. With the exception of AM-6, the V content of the products is considerably lower than that in the initial gel. About $80 \%$ of the $\mathrm{V}$ in the initial gel is built into the framework of the samples. The $\mathrm{K} /(\mathrm{K}+\mathrm{Na})$ molar ratio is around 0.2 for all samples.

Morphologies of ETVS-10. Figure 5 shows the SEM images of the ETVS-10 with different V content. In line with the previous results reported by Yoon et al., ${ }^{27}$ the assynthesized ETS-10 crystals show a truncated bipyramidal shape with two smoother square surfaces and eight somewhat rougher isosceles trapezoidal surfaces. ETVS-10(0.1) and ETVS-10(0.3) exhibit a cubic shape with higher roughness of the surfaces and substantial crystal imperfections. ETVS10(0.5) and ETVS-10(0.7) have similar shapes but with much smoother surfaces. The morphologies of ETVS-10(0.9) and AM-6 resemble more that of ETS-10. The crystallites in these cases are truncated bipyramids, although with less pronounced isosceles trapezoidal surfaces than in pure ETS10. In all cases, the dimensions of crystals are several micrometers.

Local Environment Characterization of ETVS-10 by Raman Spectroscopy. The frequencies of the Raman bands related to $\mathrm{Ti}-\mathrm{O}$ stretching vibrations and their fwhm are very sensitive to the presence of defect sites in the structure of ETS10 type materials. ${ }^{28-32}$ Previous experimental and theoretical studies pointed out that the Raman band at $724 \mathrm{~cm}^{-1}$ can be used as a fingerprint of the ETS-10 structure. For the materials with a higher concentration of defect sites, the frequency of this band shifts to higher wavenumber, its intensity strongly decreases, and the fwhm increases. ${ }^{28-30,32-34}$ Similarly, the details of structural distortions in the ETS-10 lattice caused by the introduction of $\mathrm{V}$ ions into the $-\mathrm{Ti}-\mathrm{O}-\mathrm{Ti}-$ wires can be investigated by Raman spectroscopy.

Raman spectroscopy excited with $532 \mathrm{~nm}$ was employed to investigate the effect of the vanadium substitution on the local structure of lattice octahedral sites in Figure 6. The spectrum of ETS-10 is dominated by a Raman band at $724 \mathrm{~cm}^{-1}$, which is the characteristic for the $\mathrm{Ti}-\mathrm{O}$ stretching vibration along the 

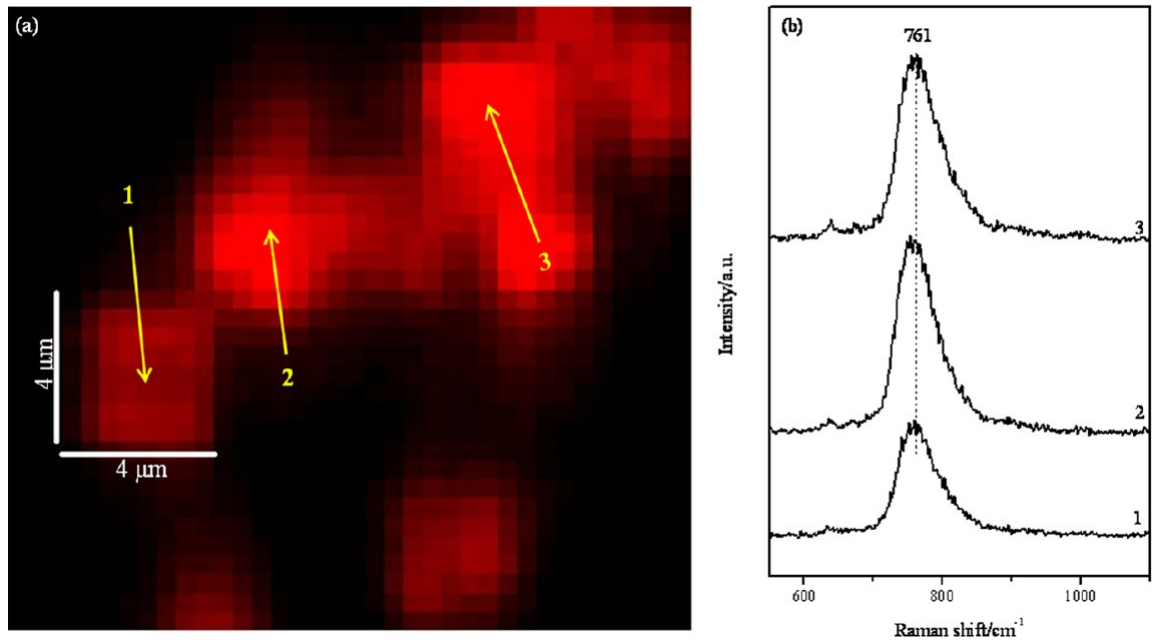

Figure 7. (a) Raman microscopy imaging of ETVS-10(0.5) (red color represents the intensity of the Raman band at $761 \mathrm{~cm}^{-1}$ ) and (b) Raman spectra of ETVS-10(0.5) at three selected spots corresponding to the numbers in part a.
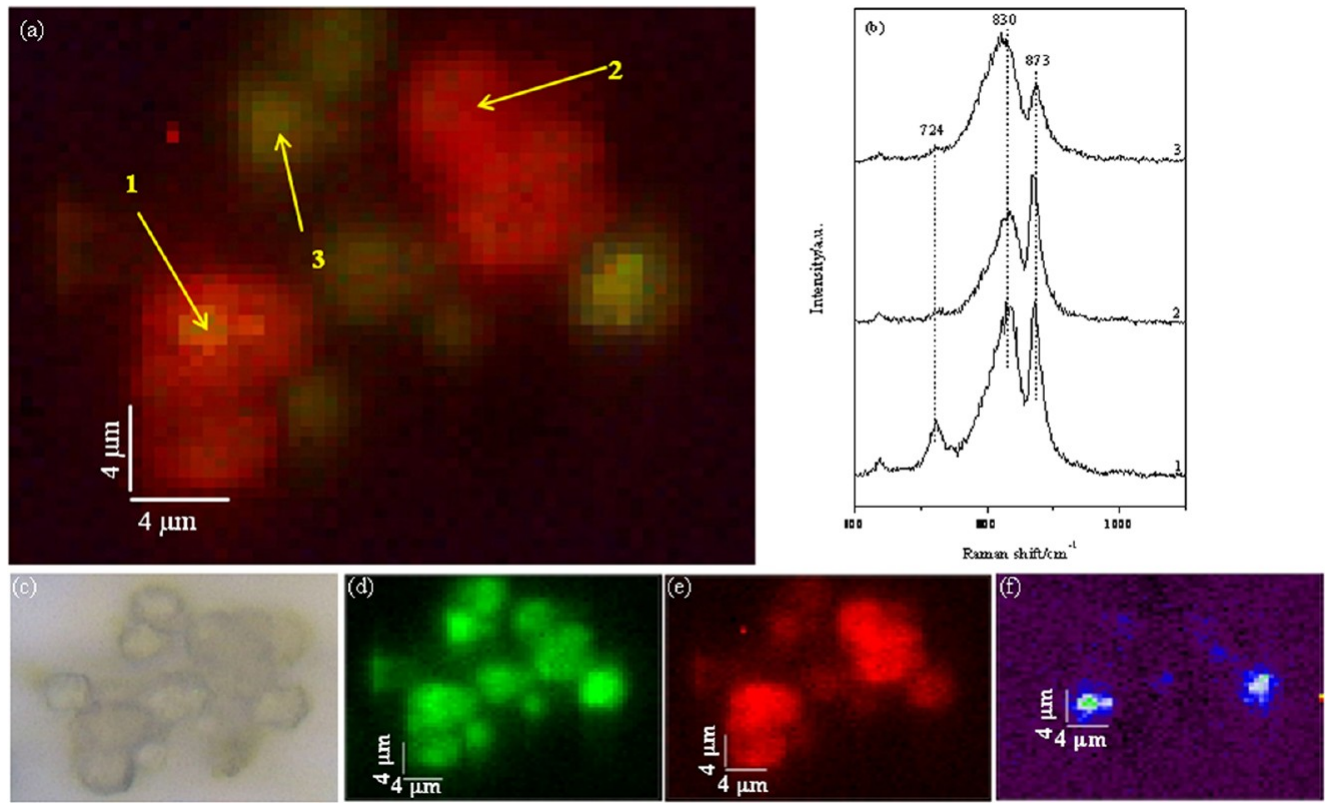

Figure 8. Raman microscopy imaging analysis of ETVS-10(0.9) with (a) Raman intensity maps (blue, green, and red represent bands at 724, 830, and $873 \mathrm{~cm}^{-1}$, respectively), (b) Raman spectra at different spots corresponding to the numbers in part a, (c) optical microscopy image, (d) Raman intensity maps at $830 \mathrm{~cm}^{-1}$, (e) Raman intensity maps at $873 \mathrm{~cm}^{-1}$, and (f) Raman intensity maps at $724 \mathrm{~cm}^{-1}$.

Ti-O-Ti wires. ${ }^{28,32,35,36}$ Compared with ETS-10, the Raman frequency of ETVS-10(0.1) is slightly shifted to higher wavenumber $\left(\sim 6 \mathrm{~cm}^{-1}\right)$ and the band has also slightly broadened. With a further increase of the $\mathrm{V}$ content, the Raman frequency shifts gradually to $742,761,777$, and 830 $\mathrm{cm}^{-1}$ for ETVS-10(0.3), ETVS-10(0.5), ETVS-10(0.7), and ETVS-10(0.9), respectively. Simultaneously, the bands become substantially broader as compared to ETS-10. For ETVS10(0.9), a Raman band at $873 \mathrm{~cm}^{-1}$ becomes apparent in the spectra. The spectrum of AM- 6 shows a Raman band at 867 $\mathrm{cm}^{-1}$, which is the characteristic for the $\mathrm{V}-\mathrm{O}$ stretching vibration mode along the $\mathrm{V}-\mathrm{O}-\mathrm{V}$ wires. ${ }^{24,37}$ Thus, the distinct Raman band at $873 \mathrm{~cm}^{-1}$ should be ascribed to the $\mathrm{V}-\mathrm{O}$ stretching vibration in ETVS-10(0.9) similar to that in AM-6. ${ }^{20}$

In the case of ETVS-10, the introduction of lattice vanadium sites acts as "defects" by interrupting the $-\mathrm{Ti}-\mathrm{O}-\mathrm{Ti}-$ wires, and the average consecutive length of $-\mathrm{Ti}-\mathrm{O}-\mathrm{Ti}-$ will decrease due to the increasing $\mathrm{V}$ content. Thus, the frequency shift of the Ti species to higher wavenumber with increasing $\mathrm{V}$ content reveals the increasing possibility of $\mathrm{Ti}$ atoms meeting with $\mathrm{V}$ atoms via the formation of $\mathrm{Ti}-\mathrm{O}-\mathrm{V}$ in the ETVS-10. The absence of the Raman bands of the $\mathrm{V}-\mathrm{O}$ stretching vibration in ETVS-10 samples with lower $\mathrm{V}$ content than ETVS-10(0.9) suggests that V-O species are highly isolated. However, for ETVS-10(0.9), the appearance of the Raman band at $873 \mathrm{~cm}^{-1}$ indicates that a number of the incorporated $\mathrm{V}$ atoms are in the form of aggregated $-\mathrm{V}-\mathrm{O}-\mathrm{V}-$ species. On the basis of the above discussions, a possible model is proposed in Scheme 2. The $\mathrm{V} /(\mathrm{V}+\mathrm{Ti})$ ratios in the models correspond to the values measured by ICP in the synthesized materials. These are typically lower than the ratios in the initial gel. The distribution of $\mathrm{Ti}$ and $\mathrm{V}$ fragments is relatively homogeneous for ETVS-10(0.1), ETVS-10(0.3), ETVS-10(0.5), and ETVS$10(0.7)$ deduced by the single Raman band and Raman 


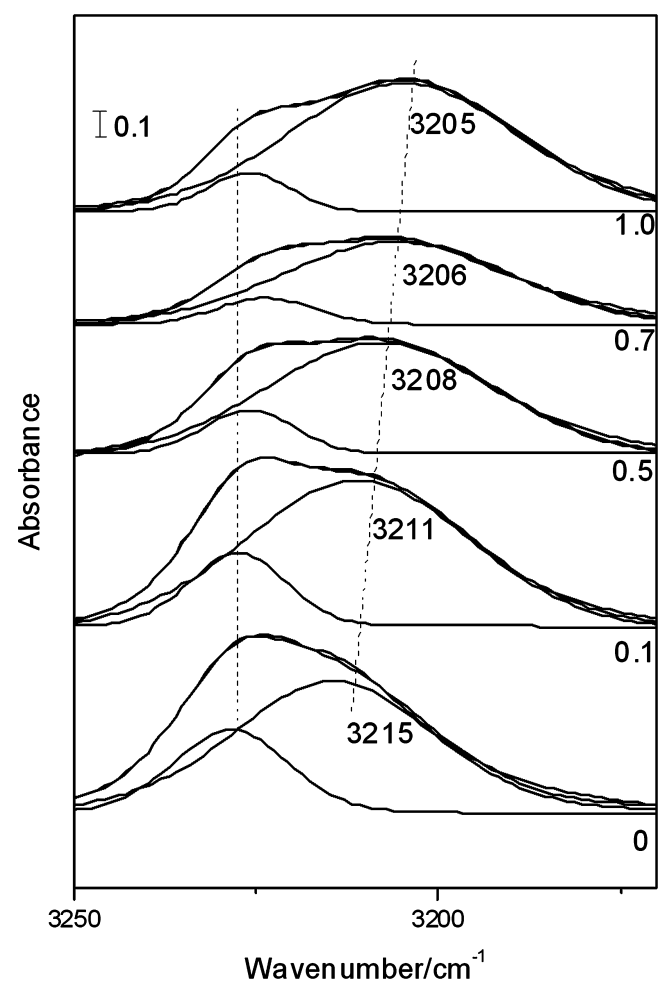

Figure 9. FTIR spectra of acetylene on ETVS-10 samples with different $\mathrm{V}$ content at the same equilibrium pressure of $0.5 \mathrm{mbar}$.

microscopy imaging analysis. For ETVS-10(0.9), the appearance of a band at $873 \mathrm{~cm}^{-1}$ indicates the formation of aggregated $\mathrm{V}-\mathrm{O}-\mathrm{V}$ species. Doren and Lobo et al. have shown that the oxidation state of the $\mathrm{V}$ in the chains of ETVS-10 is mainly $\mathrm{V}^{4+}$, and still $\mathrm{V}^{5+}$ at the terminal sites of the chains. ${ }^{19-22}$

The Distribution of Ti and V Species of ETVS-10 by Raman Microscopy Imaging. The distribution of $\mathrm{Ti}$ and $\mathrm{V}$ species in ETVS-10(0.5) and ETVS-10(0.9) is further characterized by Raman microscopy imaging. For ETVS$10(0.5)$ a homogeneous distribution of the intensity of the characteristic Raman band at $761 \mathrm{~cm}^{-1}$ is observed (Figure 7). The Raman spectra of the individual crystallites resemble the spectrum of the powder. The imaging result proves that the single Raman band of ETVS-10 (Figure 2, 0.1 to 0.7) corresponds for the homogeneous $\mathrm{V}$ distribution.

In contrast, the Raman image for ETVS-10(0.9) evidence a relatively heterogeneous distribution of $\mathrm{V}$ and $\mathrm{Ti}$. The Raman spectra of individual crystallites exhibit very different intensity ratios for the bands at 830 and $867 \mathrm{~cm}^{-1}$ (Figure $8 \mathrm{~b}$ ). Although the distribution of the Ti-rich regions (Raman band at 830 $\mathrm{cm}^{-1}$ ) is quite homogeneous for all particles (Figure $8 \mathrm{~d}$ ), the distribution of $\mathrm{V}-\mathrm{O}-\mathrm{V}$ structural units is much less uniform (Figure 8e). It appears that the relative concentration of $\mathrm{V}$-rich domains is higher for the larger crystals. In addition, the presence of pure ETS-10 deriving from the seeds is observed by their weak signature band at $724 \mathrm{~cm}^{-1}$ (Figure 8f).
A series of ETVS-10 with different framework V content are investigated by ICP, SEM, Raman spectroscopy, and Raman microscopy imaging. The Raman frequencies of the signature band for $\mathrm{Ti}$ wires are used as indicators for the possibility of $\mathrm{Ti}$ atoms meeting with $\mathrm{V}$ atoms in the ETVS-10. Raman spectroscopy and Raman microscopy imaging show that the distribution of $\mathrm{Ti}$ and $\mathrm{V}$ fragments is relatively homogeneous for samples with the $\mathrm{V}$ content below 0.9. Besides, the number of basic sites can be roughly estimated by the number of hydroxyl defects, since the location of basic sites is to the oxygen adjacent to the defects sites (Scheme 1C). The number of junctions of Ti-rich and V-rich is mainly contributed by the number of defects, since the hydroxyl defects are easily formed nearby the junctions. ${ }^{20,28,38}$ As shown in Scheme 2, although the possibility of $\mathrm{Ti}$ atoms meeting with $\mathrm{V}$ atoms increases with increasing $\mathrm{V}$ content, the number of $\mathrm{Ti}$ atoms in the ETVS-10 crystal is decreasing at the same time. Consequently, the number of junctions first increases with increasing $\mathrm{V}$ content from 0 to 0.7 , and decreases with increasing $\mathrm{V}$ content to 0.9 (Scheme 1).

Acid-Base Property of ETSV-10 Samples. FTIR spectra of acetylene adsorbed on ETVS-10 are also shown in Figure $\mathrm{S} 4 \mathrm{a}-\mathrm{d}$ in the Supporting Information. Qualitatively, the spectral features observed upon $\mathrm{C}_{2} \mathrm{H}_{2}$ adsorption to ETVS-10 are similar to those for ETS-10. Figure 9 compares the FTIR spectra of adsorbed acetylene on ETVS-10 with different V content at the same equilibrium pressure of $0.5 \mathrm{mbar}$. One can see that, whereas the position of the HF feature does not depend much on the V content, the LF band undergoes an increasing red shift with increasing $\mathrm{V}$ content. Furthermore, the ratio between the LF and HF features increases at higher $\mathrm{V}$ content.

Specific adsorption of acetylene to basic sites is related to the pronounced acidity of its $\mathrm{CH}$ bonds that can form a hydrogen bond with the lattice oxygen atoms of the framework. Depending on the basicity of the adsorption sites, the strength of the resulting hydrogen-bonded adsorption complex will vary. The formation of the hydrogen-bonded complex of acetylene weakens the $\mathrm{CH}$ bond and therefore causes a red shift of the corresponding $\mathrm{CH}$ stretching vibration $\left(\nu_{\mathrm{CH}}\right)$. The higher the basicity of the adsorption sites is, the stronger the interaction with the $\mathrm{CH}$ moiety of the adsorbed molecules becomes and the larger the red shift of the $\mathrm{CH}$ stretching vibration is observed in the FTIR spectrum. The results presented suggest that the increasing framework V content in ETVS-10 increases the basicity of the sites. The basic sites in AM-6 are the strongest. ETVS-10 samples exhibit more moderate basicity, while the basic sites in ETS-10 are the weakest in this series of samples. Nonetheless, the basic sites in ETS-10 are much stronger than those in $\mathrm{NaY}$ zeolite.

A Test Reaction for Basicity. The Knoevenagel condensation (KC) is a $\mathrm{C}-\mathrm{C}$ bond forming reaction, which is widely used for the synthesis of important intermediates and end products such as perfumes, pharmaceuticals, and polymers. This reaction has also been commonly used to probe the basic catalytic properties of solid catalysts. ${ }^{7,25,39-42}$ In this way, one

\section{Table 2. Results of the KC Reaction}

\begin{tabular}{|c|c|c|c|c|c|c|c|c|}
\hline sample & ETS-10 & ETVS-10(0.1) & ETVS-10(0.3) & ETVS-10(0.5) & ETVS-10(0.7) & ETVS-10(0.9) & AM-6 & blank \\
\hline yield $/ \%^{a}$ & 35.6 & 43.1 & 44.2 & 48.7 & 58.1 & 52.4 & 44.8 & 3.5 \\
\hline
\end{tabular}

${ }^{a}$ No byproduct other than the KC product was obtained. 
could obtain information about the total number of basic sites and the relative basic strength of different base catalysts. ${ }^{42}$ The rate-controlling step of the condensation reaction on basic solids is the attack of the carbonyl group by the carbanion intermediate. $^{39,42}$ The results of the $\mathrm{KC}$ of benzaldehyde with ethyl cyanoacetate for the series of ETVS-10 samples are summarized in Table 2. With increasing $\mathrm{V}$ content from 0 to 0.7 , the ethyl $\alpha$-cyanocinnamate yield for the $\mathrm{KC}$ reaction between benzaldehyde and ethyl cyanoacetate gradually increases from $36 \%$ to $58 \%$. A further increase in the $\mathrm{V}$ content ( 0.9 and 1.0$)$ results in a pronounced decrease of the ethyl $\alpha$-cyanocinnamate yield.

The effects of number and strength of the basic sites on KC reaction are considered separately. For $\mathrm{V}$ content of 0 to 0.1 , the increase in the ECC yield is mainly due to the increase of basicity compared to the small number of junctions. For $\mathrm{V}$ contents in the range of 0.1 to 0.7 , the increase in both intrinsic basicity and the number of basic sites leads to the further increase of catalyst activity. However, because the number of basic sites associated with the structural defects substantially decreases at the high V loadings (0.9 and 1), the ECC yield drops substantially for the respective samples, despite their higher intrinsic basicity.

\section{SUMMARY}

The acid and base properties of microporous titanosilicate ETS10 were studied by coadsorption of $\mathrm{CO}$ and acetylene. The lattice oxygen centers adjacent to defect $\mathrm{Ti}-\mathrm{OH}$ sites are identified as the basic sites. The basicity of the lattice oxygens increases with increasing $\mathrm{V}$ content. The strength of the basic sites increases in the order ETS-10 < ETVS-10 < AM-6.

The introduction of vanadium ions into the ETS-10 framework changes the local environment of $\mathrm{Ti}$ wires. The Raman frequencies of the signature band for $\mathrm{Ti}$ wires are used as indicators for the possibility of $\mathrm{Ti}$ atoms meeting with $\mathrm{V}$ atoms in the ETVS-10. It is roughly used to estimate the number of basic sites of ETVS-10 samples. The V distribution of ETVS-10 is homogeneous with V content lower than 0.9.

As a function of $\mathrm{V}$ content, the activity in the Knoevenagel condensation of benzaldehyde with ethyl cyanoacetate shows a maximum for the sample with a $\mathrm{V} /(\mathrm{V}+\mathrm{Ti})$ of 0.7 . The catalytic activity is determined both by the number and the intrinsic strength of basic sites in the ETVS-10.

\section{ASSOCIATED CONTENT}

\section{S Supporting Information}

The 21T cluster model used for calculations; FTIR spectra of acetylene on $\mathrm{NaY}$; XRD patterns of ETVS-10 with different $\mathrm{V}$ content; and FTIR spectra of acetylene on ETVS-10(0.1), ETVS-10(0.5), ETVS-10(0.7), and AM-6. This material is available free of charge via the Internet at http://pubs.acs.org.

\section{AUTHOR INFORMATION}

\section{Corresponding Author}

*Fax: (+86) 41-84694447 (C.L.). E-mail: canli@dicp.ac.cn (C.L.) and e.j.m.hensen@tue.nl (E.J.M.H.).

\section{Notes}

The authors declare no competing financial interest.

\section{ACKNOWLEDGMENTS}

This work was financially supported by National Basic Research Program of China (2009CB623507), National Natural Science
Foundation of China (21003122), Knowledge Innovative Program of The Chinese Academy of Sciences (KGCX2-EW310-2), and Programme Strategic Scientific Alliances between China and The Netherlands (2008DFB50130; 08-PSA-M-01). J.P.H. would like to express gratitude to the German Research Foundation DFG (postdoctoral research grant Ho4579/1-1) and NRSC-Catalysis for funding.

\section{REFERENCES}

(1) Philippou, A.; Naderi, M.; Rocha, J.; Anderson, M. W. Catal. Lett. 1998, 53, 221-224.

(2) Rocha, J.; Brandao, P.; de Jesus, J. D. P.; Philippou, A.; Anderson, M. W. Chem. Commun. 1999, 471-472.

(3) Brandao, P.; Philippou, A.; Valente, A.; Rocha, J.; Anderson, M. Phys. Chem. Chem. Phys. 2001, 3, 1773-1777.

(4) Valente, A.; Lin, Z.; Brandao, P.; Portugal, I.; Anderson, M.; Rocha, J. J. Catal. 2001, 200, 99-105.

(5) Philippou, A.; Anderson, M. W. J. Catal. 2000, 189, 395-400.

(6) Ono, Y. J. Catal. 2003, 216, 406-415.

(7) Lima, S.; Dias, A. S.; Lin, Z.; Brandao, P.; Ferreira, P.; Pillinger, M.; Rocha, J.; Calvino-Casilda, V.; Valente, A. A. Appl. Catal., A 2008, $339,21-27$.

(8) Lercher, J. A.; Grundling, C.; EderMirth, G. Catal. Today 1996, 27, 353-376.

(9) Anderson, M. W.; Terasaki, O.; Ohsuna, T.; Philippou, A.; Mackay, S. P.; Ferreira, A.; Rocha, J.; Lidin, S. Nature 1994, 367, 347351.

(10) Knozinger, H.; Huber, S. J. Chem. Soc., Faraday Trans. 1998, 94, 2047-2059.

(11) Lavalley, J. C. Catal. Today 1996, 27, 377-401.

(12) Schoonheydt, R.; Geerlings, P.; Pidko, E.; Santen, R. A. J. Mater. Chem. 2012, DOI: 10.1039/C2JM31366A.

(13) Hadjiivanov, K. I.; Vayssilov, G. N. Adv. Catal. 2002, 47, 307511.

(14) Zecchina, A.; Bordiga, S.; Spoto, G.; Scarano, D.; Petrini, G.; Leofanti, G.; Padovan, M.; Arean, C. O. J. Chem. Soc., Faraday Trans. 1992, 88, 2959-2969.

(15) Rocha, J.; Lin, Z.; Ferreira, A.; Anderson, M. W. J. Chem. Soc., Chem. Commun. 1995, 867-868.

(16) Brandao, P.; Valente, A. A.; Rocha, J.; Anderson, M. W. Stud. Surf. Sci. Catal. 2002, 142, 327-334.

(17) Eldewik, A.; Howe, R. F. Microporous Mesoporous Mater. 2001, $48,65-71$.

(18) Anderson, M. W.; Rocha, J.; Lin, Z.; Philippou, A.; Orion, I.; Ferreira, A. Microporous Mater. 1996, 6, 195-201.

(19) Shough, A. M.; Lobo, R. F.; Doren, D. J. Phys. Chem. Chem. Phys. 2007, 9, 5096-5104.

(20) Nash, M. J.; Rykov, S.; Lobo, R. F.; Doren, D. J.; Wachs, I. J. Phys. Chem. C 2007, 111, 7029-7037.

(21) Shough, A. M.; Doren, D. J.; Nash, M.; Loho, R. F. J. Phys. Chem. C 2007, 111, 1776-1782.

(22) Ooms, K.; Polenova, T.; Shough, A. M.; Doren, D. J.; Nash, M. J.; Lobo, R. F. J. Phys. Chem. C 2009, 113, 10477-10484.

(23) Shough, A. M.; Doren, D. J.; Ogunnaike, B. Chem. Mater. 2009, $21,1232-1241$.

(24) Rocha, J.; Brandao, P.; Lin, Z.; Anderson, M. W.; Alfredsson, V.; Terasaki, O. Angew. Chem., Int. Ed. Engl. 1997, 36, 100-102.

(25) Goa, Y.; Wu, P.; Tatsumi, T. J. Catal. 2004, 224, 107-114.

(26) Kishima, M.; Okubo, T. J. Phys. Chem. B 2003, 107, 8462-8468.

(27) Jeong, N. C.; Lee, M. H.; Yoon, K. B. Angew. Chem., Int. Ed. 2007, 46, 5868-5872.

(28) Southon, P. D.; Howe, R. F. Chem. Mater. 2002, 14, 42094218.

(29) Guo, M. L.; Feng, Z. C.; Li, G. N.; Hofmann, J. P.; Pidko, E. A.; Magusin, P. C. M. M.; Guo, Q.; Weckhuysen, B. M.; Hensen, E. J. M.; Li, C. Chem._Eur. J. 2012, DOI: 10.1002/chem.201200875.

(30) Pavel, C. C.; Park, S. H.; Dreier, A.; Tesche, B.; Schmidt, W. Chem. Mater. 2006, 18, 3813-3820. 
(31) Pavel, C. C.; Zibrowius, B.; Loffler, E.; Schmidt, W. Phys. Chem. Chem. Phys. 2007, 9, 3440-3446.

(32) Xamena, F. X. L. I.; Damin, A.; Bordiga, S.; Zecchina, A. Chem. Commun. 2003, 1514-1515.

(33) Yilmaz, B.; Warzywoda, J.; Sacco, A. Nanotechnology 2006, 17, 4092-4099.

(34) Lv, L.; Zhou, J. K.; Su, F.; Zhao, X. S. J. Phys. Chem. C 2007, $111,773-778$.

(35) Damin, A.; Xamena, F. X. L.; Lamberti, C.; Civalleri, B.; Zicovich-Wilson, C. M.; Zecchina, A. J. Phys. Chem. B 2004, 108, $1328-1336$.

(36) Su, Y.; Balmer, M. L.; Bunker, B. C. J. Phys. Chem. B 2000, 104, $8160-8169$.

(37) Yeates, R. M.; Murdoch, M. J.; Southon, P. D.; Mclaughlin, A. C.; Howe, R. F.; Bonino, F.; Bordiga, S.; Damin, A. Dalton Trans. 2009, 8025-8032.

(38) Anderson, M. W.; Agger, J. R.; Hanif, N.; Terasaki, O. Microporous Mesoporous Mater. 2001, 48, 1-9.

(39) Corma, A.; Fornes, V.; Martinaranda, R. M.; Garcia, H.; Primo, J. Appl. Catal. 1990, 59, 237-248.

(40) Corma, A.; Fornes, V.; Martinaranda, R. M.; Rey, F. J. Catal. 1992, 134, 58-65.

(41) Lopezgonzalez, J. D.; Lopezpeinado, A.; Martinaranda, R. M.; Rojascervantes, M. L. Carbon 1993, 31, 1231-1236.

(42) Climent, M. J.; Corma, A.; Iborra, S.; Velty, A. J. Mol. Catal. A: Chem. 2002, 182, 327-342. 